\title{
Comprehensive analysis of the expression of sodium/potassium-ATPase a subunits and prognosis of ovarian serous cystadenocarcinoma
}

Wei Huang ${ }^{1}$, Yongjian Zhang ${ }^{1}$, Ye Xu' ${ }^{1}$, Shaoyou Yang ${ }^{2}$, Bing Li $i^{1}$, Lan Huang ${ }^{3,5^{*}}$ and Ge Lou ${ }^{1,4^{*}}$ (])

\begin{abstract}
Background: Ovarian serous cystadenocarcinoma (OSC) is the most common and lethal gynecological cancer in women worldwide; however, biomarkers to diagnose and predict prognosis of OSC remain limited. Therefore, the present study aimed to investigate whether sodium/potassium adenosine triphosphate $\left(\mathrm{Na}^{+} / \mathrm{K}^{+}\right.$-ATP)ase a-subunits (ATP1As) are helpful diagnostic and prognostic markers of OSC.

Methods: Gene expression data (RNA-Seq) of 376 patients with OSC were downloaded from The Cancer Genome Atlas (TCGA) program database. Additional databases used in our analysis included the Gene Expression Omnibus, International Cancer Genome Consortium, Genotype-Tissue Expression, the Human Protein Atlas, cBioPortal for Cancer Genomics, and Cancer Cell Line Encyclopedia.

Results: The expression levels of ATP1A1 and ATP1A3 were higher in OSC tissues than in normal ovarian tissues, whereas the expression levels of ATP1A2 and ATP1A4 were lower in OSC tissues than in normal ovarian tissues. Overexpression of ATP1A2 was significantly associated with a higher Federation of Gynecology and Obstetrics (FIGO) stage and histological grade. Increased mRNA expression of ATP1A3 was significantly associated with shorter overall survival (OS) and disease-specific survival (DSS) in patients with OSC, whereas higher expression of ATP1A4 was associated with favorable OS and DSS. Multivariate analysis showed that primary therapy outcome, residual tumor, and mRNA expressions of ATP1A3 and ATP1A4 were independent prognostic factors for both OS and DSS in patients with OSC. Moreover, ATP1A1 staining was abundant in tumor tissues. A high expression of ATP1A3 was significantly correlated with poor OS and DSS in the subgroup of patients aged $\geq 60$ years and with FIGO stage III, histological grade G3, and TP53 mutation. Mutation frequencies of the ATP1As were 3-5\%.
\end{abstract}

Conclusions: These results indicate that the ATP1A gene family could be potential diagnostic or prognostic markers of OSC. In addition, ATP1As may be effective therapeutic targets in the treatment of OSC.

Keywords: Adenosine triphosphate, Ovary, Cystadenocarcinoma, Gynecology, Gene expression

*Correspondence: huanglanhmu@163.com; lougehmu@163.com

${ }^{4}$ Department of Gynecology Oncology, Tumor Hospital of Harbin Medical University, 150 Haping Road, Harbin 150081, Heilongjiang, China

${ }^{5}$ Department of Medical Oncology, Tumor Hospital of Harbin Medical University, Harbin 150081, Heilongjiang, China

Full list of author information is available at the end of the article

\section{Background}

Ovarian cancer (OC) is a gynecological malignant tumor associated with high mortality rates and has seriously impaired the health of women worldwide [1]. In nearly $70 \%$ of cases, OC has already spread to the pelvic and abdominal organs by the time of the initial diagnosis due

(c) The Author(s) 2020. This article is licensed under a Creative Commons Attribution 4.0 International License, which permits use, sharing, adaptation, distribution and reproduction in any medium or format, as long as you give appropriate credit to the original author(s) and the source, provide a link to the Creative Commons licence, and indicate if changes were made. The images or other third party material in this article are included in the article's Creative Commons licence, unless indicated otherwise in a credit line to the material. If material is not included in the article's Creative Commons licence and your intended use is not permitted by statutory regulation or exceeds the permitted use, you will need to obtain permission directly from the copyright holder. To view a copy of this licence, visit http://creativecommons.org/licenses/by/4.0/. The Creative Commons Public Domain Dedication waiver (http://creativecommons.org/publicdomain/zero/1.0/) applies to the data made available in this article, unless otherwise stated in a credit line to the data. 
to the asymptomatic nature of this cancer in early stages and the limited predictive biomarkers [2]. In addition, the prognosis of advanced $\mathrm{OC}$ is extremely poor, with a 5 -year survival rate of only $30 \%$ [3]. Ovarian serous cystadenocarcinoma (OSC) accounts for nearly $40-60 \%$ of epithelial OCs and is the most common and most lethal pathological type of OCs [4]. Therefore, identification of biomarkers for early diagnosis and prognosis prediction of OSC remains a crucial clinical challenge of important clinical significance.

Sodium/potassium adenosine triphosphate $\left(\mathrm{Na}^{+} / \mathrm{K}^{+}\right.$ATP)ase (ATP1A) is a type of ubiquitous transmembrane protein expressed widely in mammalian cells, and it plays an important role in maintaining the electrochemical gradient across the cell membrane [5]. It mainly comprises a catalytic $\alpha$ subunit and a regulatory $\beta$ subunit. The $\alpha$ subunit has four isoforms: $\alpha 1$ (ATP1A1), $\alpha 2$ (ATP1A2), $\alpha 3$ (ATP1A3), and $\alpha 4$ (ATP1A4). The $\beta$ subunit has three isoforms: $\beta 1$ (ATP1B1), $\beta 2$ (ATP1B2), and $\beta 3$ (ATP1B3) [5]. Different combinations of $\alpha$ and $\beta$ subunits can form different subtypes of $\mathrm{Na}^{+} / \mathrm{K}^{+}$-ATPase, and their distribution is tissue specific.

Previous studies have reported abnormal expressions in some members of the ATP1A gene family with prognostic value [6-10]. It is reported that ATP1A1 is overexpressed in clinical specimens and cell lines of nonsmall cell lung cancer. Moreover, knockdown of ATP1A1 impaired the proliferation and migration of tumor cells [6]. Elevated levels of ATP1A1 and ATP1A3 have been reported in patients with medulloblastoma [7]. Overexpressed ATP1B3 in gastric cancer promotes tumor proliferation, invasion, anti-apoptosis and cell-cycle arrest. Mechanically, ATP1B3 promotes the malignant progression of gastric cancer via the phosphatidylinositol 3-kinase (PI3K)/protein kinase B (AKT) signaling pathway [8]. High expression of ATP1B2 has been associated with poor prognosis of patients with glioblastoma, and downregulation of ATP1B2 can inhibit cell growth and induce cell apoptosis and cell-cycle arrest [9]. In addition, the expression of ATP1B2 in glioblastoma stem-like cells was significantly increased, suggesting its association with the stemness of tumor cells [9]. A previous study has also found that the expression of ATP1As and ATP1Bs can be used as predictors of clinical outcomes in bladder cancer [10]. Nevertheless, the role of distinct ATP1A gene family members in the development and progression of OSC has not been fully elucidated.

In the present study, we comprehensively analyzed the expression profiles of patients with OSC based on The Cancer Genome Atlas (TCGA) database and analyzed the correlation between the ATP1A gene family and clinically related information, including prognosis information. In addition, we used the $\mathrm{OC}$ clinical data in the
Gene Expression Omnibus (GEO) database and International Cancer Genome Consortium (ICGC) database for further verification and analysis. We also interpreted the results of immunohistochemistry based on gene expression in OSC and normal tissue samples and validated them in patient samples. Finally, we analyzed the mRNA expression of this gene family in pan-cancer tissues and cell lines. Our results therefore suggest that the ATP1A gene family members as potential diagnostic or prognostic markers of OSC.

\section{Materials and methods \\ RNA-sequencing (RNA-Seq) patient data and bioinformatics analysis}

We collected RNA-Seq data and the corresponding clinical information of patients with OSC from the OC project of the TCGA database [11]. A total of 376 cases were obtained from the TCGA cohort after discarding cases without clinical information. The RNA-Seq data of level 3 HTSeq fragments per kilobase per million were converted to the transcripts per million reads format for further analysis. Unavailable or unknown clinical information was considered missing values. The RNA-Seq data of normal ovarian tissue samples were downloaded from the standardized Genotype-Tissue Expression (GTEx) [12] database on the Xena platform (https:// xenabrowser.net/) [13] as control samples. In addition, we downloaded the expression profile data set and clinical information data of $\mathrm{OC}$ in the Ovarian Cancer-AU (OV-AU) dataset from the ICGC (https://dcc.icgc.org/) database. The samples included 81 OC samples and 30 normal control samples. Clinical features of patients with OC from the ICGC database are shown in Additional file 1: Table S1. Based on the GPL570 platform ([HGU133_Plus_2] Affymetrix Human Genome U133 Plus 2.0 Array), we used the $\mathrm{R}$ language GEO query package [14] to download and analyze the OC expression profile data set GSE26193 [15] from the GEO database. Homo sapiens was selected as the species, and a total of 107 OC samples were obtained. Clinical features of patients with OC from GSE26193 are shown in Additional file 1: Table S2. We used the built-in function of limma package [16] to correct the expression profile data matrix of OC in the ICGC and GEO datasets; extract the expression matrixes of ATP1A1, ATP1A2, ATP1A3, and ATP1A4; and analyze the clinical data.

\section{Human Protein Atlas (HPA)}

HPA (https://www.proteinatlas.org) is a website based on tumor immunohistochemical expression data and contains nearly 20 of the most common types of cancer. Each tumor type includes 12 individual tumors [17]. Users can identify tumor-specific protein expression patterns that 
are differentially expressed in a given type of tumor. In the present study, direct comparison of protein expression of different ATP1A gene family members between human normal and OSC tissue samples was performed by analysis of immunohistochemistry images.

\section{Broad Institute Cancer Cell Line Encyclopedia (CCLE)}

The Broad CCLE (https://portals.broadinstitute.org/ccle) is a tumor genomics research project led by the Broad Institute, which collates the data of more than 1000 tumor cell lines [18]. In the present study, we directly compared the mRNA expression of the ATP1A gene family members in different cancer cell lines.

\section{cBioPortal}

cBioPortal (www.cbioportal.org), an online open access website, is a resource for exploring, visualizing, and analyzing multidimensional cancer genomics data [19]. In the present study, we analyzed the mutation frequency of the four members of the ATP1A gene family based on the cBioPortal database.

\section{Clinical samples and immunohistochemistry staining}

The cancer and paracancerous tissues of six patients with OSC were embedded in paraffin and cut into tissue sections. These sections were placed in xylene to dewax and rehydrated with gradient alcohol. EDTA (pH 9.0) was used for antigen recovery, and 3\% hydrogen peroxide was used to block endogenous peroxidase. The primary antibodies were added, and the sections were incubated at $4{ }^{\circ} \mathrm{C}$ overnight. Then, the sections were incubated with secondary antibodies and stained with $3^{\prime}$-diaminobenzidine. The primary antibodies used were ATP1A1 (1: 200; Proteintech; 14418-1-AP), ATP1A2 (1: 200; Proteintech; 16836-1-AP), and ATP1A3 (1: 200; Proteintech; 10868$1-\mathrm{AP})$. All patients received no treatment before surgery. The study was approved by Ethics Committee of the Cancer Hospital of Harbin Medical University (Harbin, China), and all patients signed an informed consent form.

\section{Statistical methods}

Statistical analysis was performed using the R software (version 3.6.2). Wilcoxon rank sum test was used to analyze the expression of the ATP1A gene family members in normal and cancer tissues. Receiver operating characteristic (ROC) curve was used to analyze the sensitivity and specificity of the ATP1A gene family members in predicting the prognosis of OSC and OC. Kruskal-Wallis test and Wilcoxon signed-rank test were used to analyze the relationship between the clinicopathological features and the expression of ATP1A genes. Cox regression analysis or Kaplan-Meier method was used to evaluate the prognostic value of ATP1A genes. In Cox regression analysis, the variables with $p<0.1$ in univariate Cox regression were included in multivariate Cox regression. A two-sided $p$ value of $<0.05$ was considered to be statistically significant.

\section{Results}

\section{Patient characteristics}

As shown in Table 1, 376 cases of primary OSC with clinical and gene expression data were downloaded from the TCGA database. Among these, 178 patients (47.3\%) were aged $>60$ years. Federation of Gynecology and Obstetrics (FIGO) stage I disease was found in 1 patient (0.3\%), stage II in 22 (5.9\%), stage III in 293 (78.6\%), and stage IV in 57 (15.3\%). The histological grades, G1, G2, G3, and G4 were found in $0.3 \%, 11.5 \%, 88.0 \%$, and $0.3 \%$ of the patients, respectively. The cancer status included 71 without $(21.3 \%)$ and 262 with $(78.7 \%)$ tumors. The patients were divided into four groups according to the primary therapy outcome: progressive disease (PD), 27 (8.9\%); partial response (PR), 43 (14.1\%); stable disease (SD), 22 (7.2\%); and complete response (CR), 213 (69.8\%). Residual tumors were found in 267 of the 376 total cases (23.5\%), lymphatic invasion in 100 of 148 cases $(67.6 \%)$, and venous invasion in 63 of 103 cases (61.2\%). Lesions occurred in the bilateral ovaries of 253 cases. Mutations of TP53 and breast cancer susceptibility genes (BRCA) were found in 248 and 25 cases, respectively. Of the patients in this cohort, $61.2 \%$ finally succumbed to OSC (Table 1).

We compared the hazard ratios (HR) with 95\% confidence interval (CI) ranges among patient information parameters. Univariate analysis identified primary therapy outcome $(p<0.001)$, age $(p=0.032)$, residual tumor $(p<0.001)$, ATP1A3 $(p<0.001)$, and ATP1A4 $(p=0.03)$ as prognostic factors for OS (Table 2). Multivariate analysis showed that primary therapy outcome $(p<0.001)$, residual tumor $(p=0.004)$, ATP1A2 $(p=0.006)$, ATP1A3 $(p<0.001)$, and ATP1A4 $(p<0.001)$ were independent risk factors for OS (Table 2).

Univariate analysis identified primary therapy outcome $(p<0.001)$, residual tumor $(p<0.001)$, ATP1A3 $(p=0.002)$, and ATP1A4 $(p=0.023)$ as prognostic factors for DSS (Table 3). Multivariate analysis showed that primary therapy outcome $(p<0.001)$, residual tumor $(p=0.001), \operatorname{ATP} 1 \mathrm{~A} 3(p=0.006)$, and ATP1A4 $(p=0.017)$ were independent risk factors for DSS (Table 3).

\section{Correlation between expression of ATP1A genes and the clinical characteristics}

The expression of ATP1A gene family members in OSC and normal tissues were significantly different. ATP1A1 and ATP1A3 were highly expressed in tumor tissues, whereas ATP1A2 and ATP1A4 were highly expressed 
Table 1 Clinical characteristics of 376 ovarian cancer patients in TCGA database

\begin{tabular}{|c|c|}
\hline Characteristics & $\begin{array}{l}\text { Total } \\
\mathrm{N}=376(\%)\end{array}$ \\
\hline \multicolumn{2}{|l|}{ Age } \\
\hline$<60$ & $198(52.7)$ \\
\hline$\geq 60$ & $178(47.3)$ \\
\hline \multicolumn{2}{|l|}{ FIGO stage } \\
\hline Stage I & $1(0.3)$ \\
\hline Stage II & $22(5.9)$ \\
\hline Stage III & $293(78.6)$ \\
\hline Stage IV & $57(15.3)$ \\
\hline \multicolumn{2}{|l|}{ Histologic grade } \\
\hline G1 & $1(0.3)$ \\
\hline $\mathrm{G} 2$ & $42(11.5)$ \\
\hline G3 & $322(88.0)$ \\
\hline G4 & $1(0.3)$ \\
\hline \multicolumn{2}{|l|}{ Recurrence } \\
\hline No & $176(46.8)$ \\
\hline Yes & $200(53.2)$ \\
\hline \multicolumn{2}{|l|}{ Tumor status } \\
\hline Tumor free & $71(21.3)$ \\
\hline With tumor & $262(78.7)$ \\
\hline \multicolumn{2}{|c|}{ Primary therapy outcome } \\
\hline PD & $27(8.9)$ \\
\hline SD & $22(7.2)$ \\
\hline$P R$ & $43(14.1)$ \\
\hline$C R$ & $213(69.8)$ \\
\hline \multicolumn{2}{|l|}{ Tumor residual } \\
\hline NRD & 66 (19.8) \\
\hline $\mathrm{RD}$ & $267(80.2)$ \\
\hline \multicolumn{2}{|c|}{ Lymphatic invasion } \\
\hline No & $48(32.4)$ \\
\hline Yes & $100(67.6)$ \\
\hline \multicolumn{2}{|l|}{ Venous invasion } \\
\hline No & $40(38.8)$ \\
\hline Yes & $63(61.2)$ \\
\hline \multicolumn{2}{|c|}{ Anatomic subdivision } \\
\hline Unilateral & $101(28.5)$ \\
\hline Bilateral & $253(71.5)$ \\
\hline \multicolumn{2}{|l|}{ TP53 mutation } \\
\hline No & $26(9.5)$ \\
\hline Yes & $248(90.5)$ \\
\hline \multicolumn{2}{|l|}{ BRCA mutation } \\
\hline No & $249(90.9)$ \\
\hline Yes & $25(9.1)$ \\
\hline \multicolumn{2}{|l|}{ OS event } \\
\hline Alived & $146(38.8)$ \\
\hline Dead & $230(61.2)$ \\
\hline
\end{tabular}

$P D$ progression disease, $S D$ stable disease, $P R$ partial response, $C R$ complete response, $N R D$ no residual disease, $R D$ residual disease, $O S$ overall survival in normal tissues (all $p<0.001$ ) (Fig. 1a-d). Based on the OV-AU dataset, we found that ATP1A2 was highly expressed in OC tissues $(\mathrm{p}<0.001)$, whereas ATP1A3 was highly expressed in normal tissues $(p=0.002)$. In addition, there was no difference in the expression of ATP1A1 and ATP1A4 between OC and normal tissues (Additional file 2: Figure S1A-D). To evaluate the expression of the ATP1A gene family members in human pan-cancers, the RNA-Seq data from the TCGA and GTEx databases were further analyzed. Differential expression between the tumor and adjacent normal tissues for ATP1A1-4 across all TCGA tumors is shown in Additional file 3: Figure S2. ATP1A1 expression was significantly higher in cholangiocarcinoma, skin cutaneous melanoma and thymoma (THYM) (all $p<0.001)$ than in the adjacent normal tissues. ATP1A2 expression was significantly lower in breast invasive carcinoma, bladder urothelial carcinoma and colon adenocarcinoma (all $p<0.001$ ) than in the adjacent normal tissues. ATP1A3 expression was significantly higher in adrenocortical carcinoma $(p<0.001)$, THYM $(p<0.001)$ and pheochromocytoma and paraganglioma $(p<0.01)$ than in the adjacent normal tissues. ATP1A4 expression was significantly higher in BRCA, lymphoid neoplasm diffuse large B-cell lymphoma and lung squamous cell carcinoma (all $p<0.001$ ) (Additional file 3: Figure S2). In addition, the mRNA expression of the ATP1A gene family members in pan-cancer cell lines was also analyzed based on the CCLE database (Additional file 4: Figure S3). As observed, ATP1A1 was highly expressed in Ewing's-sarcoma, melanoma, and colorectal carcinoma, whereas ATP1A3 was highly expressed in neuroblastoma, Burkitt lymphoma, and T-lymphocytic leukemia. Conversely, the expression of ATP1A2 and ATP1A4 was lower in most tumor cell lines (Additional file 4: Figure S3).

Next, we analyzed the sensitivity and specificity of the ATP1A gene family members in predicting the diagnosis of OSC by ROC curve. The area under the curve (AUC) for ATP1A1, ATP1A2, ATP1A3, and ATP1A4 were $0.829,0.963,0.892$ and 0.778 , respectively (Fig. 1e-h). The results from the OV-AU dataset are consistent with those from the TCGA database. The AUC for ATP1A1, ATP1A2, ATP1A3, and ATP1A4 in patients with OC were $0.555,0.729,0.704$, and 0.507, respectively (Additional file 2: Figure $\mathrm{S} 1 \mathrm{E}-\mathrm{H}$ ). These results suggested that the ATP1A gene family members are potential diagnostic biomarkers for both OSC and OC.

Moreover, we analyzed the correlation between the expression of the ATP1A gene family members and the clinical features, as revealed by the Kruskal-Wallis test and Wilcoxon signed-rank test. Significant correlation was noted between ATP1A3 $(p=0.019)$ and FIGO stage, but no significant correlations were found 
Table 2 Univariate and multivariate analysis of clinical variables and ATP1As for OS

\begin{tabular}{|c|c|c|c|c|}
\hline \multirow[t]{2}{*}{ Characteristics } & \multicolumn{2}{|l|}{ Univariate analysis } & \multicolumn{2}{|l|}{ Multivariate analysis } \\
\hline & Hazard ratio $(95 \% \mathrm{Cl})$ & $p$-value & Hazard ratio $(95 \% \mathrm{Cl})$ & $p$-value \\
\hline FIGO stage (stage I-II vs. stage III-IV) & $2.085(0.925-4.699)$ & 0.076 & $1.638(0.392-6.854)$ & 0.499 \\
\hline Histologic grade (G1-2 vs. G3-4) & $1.194(0.797-1.789)$ & 0.389 & & \\
\hline Primary therapy outcome (PR-CR vs. SD-PD) & $0.306(0.207-0.451)$ & $<0.001$ & $0.247(0.161-0.38)$ & $<0.001$ \\
\hline Age $(<60$ vs. $\geq 60)$ & $1.329(1.025-1.722)$ & 0.032 & $1.305(0.948-1.794)$ & 0.102 \\
\hline Tumor residual (NRD vs. RD) & $2.302(1.479-3.583)$ & $<0.001$ & $2.149(1.285-3.594)$ & 0.004 \\
\hline Lymphatic invasion (no vs. yes) & $1.422(0.839-2.411)$ & 0.191 & & \\
\hline Venous invasion (no vs. yes) & $0.905(0.487-1.683)$ & 0.753 & & \\
\hline Anatomic subdivision (unilateral vs. bilateral) & $1.041(0.768-1.41)$ & 0.798 & & \\
\hline TP53 mutation (no vs. yes) & $0.692(0.423-1.132)$ & 0.143 & & \\
\hline BRCA mutation (no vs. yes) & $0.65(0.361-1.171)$ & 0.152 & & \\
\hline ATP1A1 (low vs. high) & $1.148(0.885-1.49)$ & 0.298 & & \\
\hline ATP1A2 (low vs. high) & $1.257(0.968-1.632)$ & 0.086 & $1.564(1.134-2.157)$ & 0.006 \\
\hline ATP1A3 (low vs. high) & $1.6(1.232-2.077)$ & $<0.001$ & $1.932(1.397-2.673)$ & $<0.001$ \\
\hline ATP1A4 (low vs. high) & $0.748(0.575-0.972)$ & 0.03 & $0.555(0.4-0.771)$ & $<0.001$ \\
\hline
\end{tabular}

Table 3 Univariate and multivariate analysis of clinical variables and ATP1As for DSS

\begin{tabular}{|c|c|c|c|c|}
\hline \multirow[t]{2}{*}{ Characteristics } & \multicolumn{2}{|l|}{ Univariate analysis } & \multicolumn{2}{|l|}{ Multivariate analysis } \\
\hline & Hazard ratio $(95 \% \mathrm{Cl})$ & $p$-value & Hazard ratio $(95 \% \mathrm{Cl})$ & $p$-value \\
\hline FIGO stage (stage I-II vs. stage III-IV) & $2.244(0.922-5.462)$ & 0.075 & $1.092(0.257-4.639)$ & 0.905 \\
\hline Histologic grade (G1-2 vs. G3-4) & $1.313(0.833-2.07)$ & 0.24 & & \\
\hline Primary therapy outcome (SD-PD vs. PR-CR) & $0.299(0.201-0.443)$ & $<0.001$ & $0.296(0.169-0.517)$ & $<0.001$ \\
\hline Age $(<60$ vs. $\geq 60)$ & $1.248(0.944-1.65)$ & 0.12 & & \\
\hline Tumor residual (NRD vs. RD) & $2.559(1.572-4.166)$ & $<0.001$ & $2.991(1.526-5.86)$ & 0.001 \\
\hline Lymphatic invasion (no vs. yes) & $1.407(0.816-2.425)$ & 0.219 & & \\
\hline Venous invasion (no vs. yes) & $0.846(0.45-1.591)$ & 0.604 & & \\
\hline Anatomic subdivision (unilateral vs. bilateral) & $1.034(0.747-1.431)$ & 0.841 & & \\
\hline TP53 mutation (no vs. yes) & $0.643(0.386-1.07)$ & 0.089 & $1.026(0.565-1.861)$ & 0.934 \\
\hline BRCA mutation (no vs. yes) & $0.596(0.313-1.134)$ & 0.115 & & \\
\hline ATP1A1 (low vs. high) & $1.135(0.857-1.501)$ & 0.377 & & \\
\hline ATP1A2 (low vs. high) & $1.304(0.984-1.727)$ & 0.064 & $1.413(0.958-2.085)$ & 0.082 \\
\hline ATP1A3 (low vs. high) & $1.572(1.188-2.081)$ & 0.002 & $1.723(1.169-2.54)$ & 0.006 \\
\hline ATP1A4 (low vs. high) & $0.721(0.544-0.956)$ & 0.023 & $0.611(0.408-0.916)$ & 0.017 \\
\hline
\end{tabular}

between ATP1A1 $(p=0.395)$, ATP1A2 $(p=0.492)$, ATP1A4 $(p=0.07)$, and FIGO stage (Fig. $2 \mathrm{a}-\mathrm{d})$. In addition, ATP1A3 $(p<0.001)$ was significantly associated with histological grade, whereas ATP1A1 $(p=0.913)$, ATP1A2 $(p=0.716)$, and ATP1A4 ( $p=0.727)$ were not (Fig. $2 \mathrm{e}-\mathrm{h})$. Although no correlation was found between ATP1As and lymphatic invasion, the $p$ value of ATP1A3 was close to 0.05 , suggesting that the lack of significance may be due to a limitation of the number of patients (Fig. 2i-l). By analyzing the GSE26193 dataset, no significant correlations were found between ATP1A1 $(p=0.21)$, ATP1A2 $(p=0.35), \operatorname{ATP} 1 \mathrm{~A} 3(p=0.9), \operatorname{ATP} 1 \mathrm{~A} 4 \quad(p=0.59)$, and FIGO stage (Additional file 5: Figure S4A-D). In addition, we found a significant correlation between ATP1A1 and histological grade $(p=0.008)$, whereas ATP1A2 $(p=0.87)$, ATP1A3 $(p=0.882)$, and ATP1A4 $(p=0.453)$ were not (Additional file 5: Figure S4E-H).

Based on these mRNA expression patterns of the ATP1A gene family members in OSC, we next explored the protein expression patterns of ATP1As in OSC using HPA. As shown in Fig. 3, ATP1A1 was highly expressed in the OSC tissue than in the normal ovarian tissues 

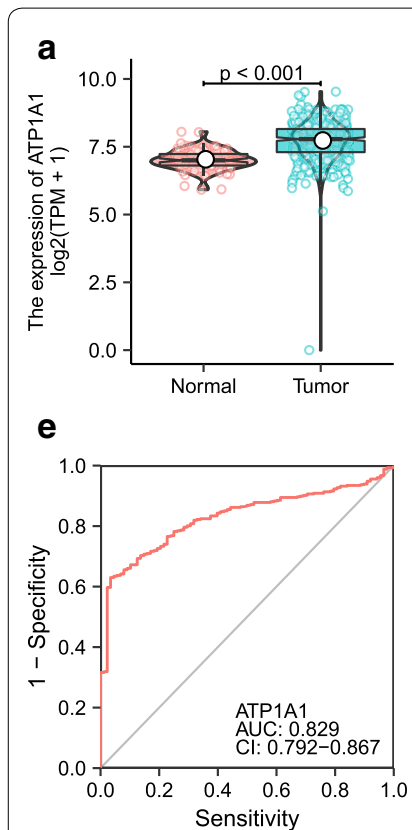

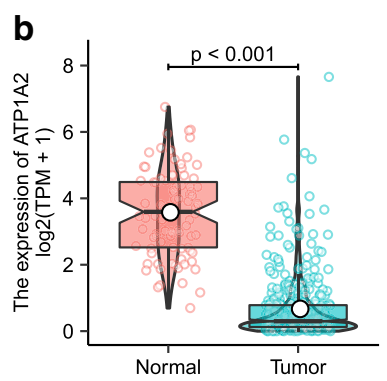

f

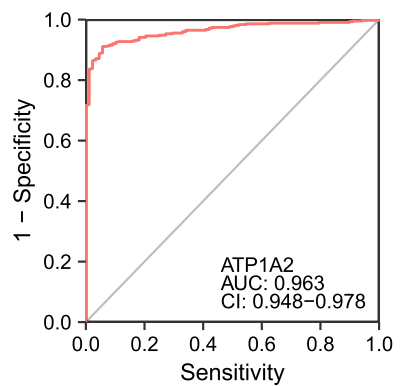

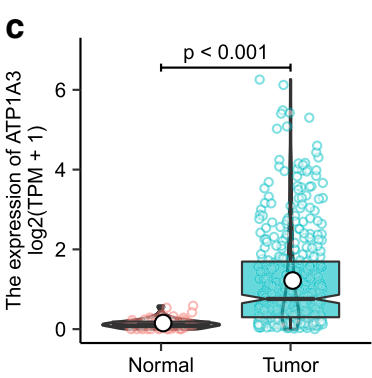

g

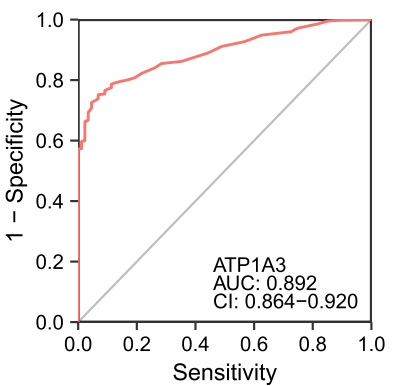

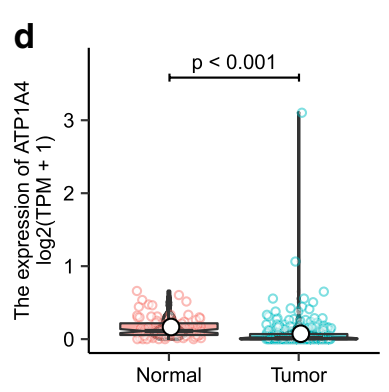

h

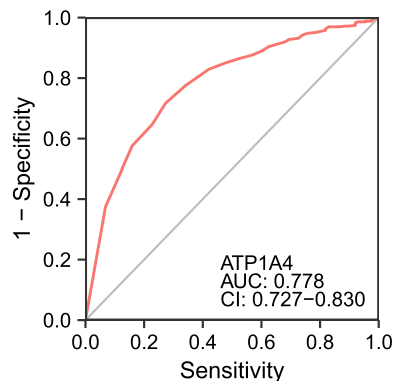

Fig. 1 Expression of ATP1A gene family members in ovarian serous cystadenocarcinoma (OSC) and its diagnostic value. a-d Differential expression analysis of ATP1A gene family members between OSC samples based on the TCGA database and normal ovarian samples based on the GTEx database. e-h Receiver-operating characteristic (ROC) curves for ATP1A gene family members for diagnosis of OSC. (AUC area under curve, Cl confidence interval, $N$ normal, $T$ tumor)

(Fig. 3a). In addition, the protein expression of ATP1A2 and ATP1A3 was low in both normal and OSC tissues (Fig. 3b, c). A lack of protein expression patterns of ATP1A4 genes in the database at present precluded our analysis of this protein.

\section{Prognostic value of mRNA expression of ATP1A gene family members in patients with OSC}

We used a Kaplan-Meier plotter (http://kmplot.com/ analysis/) to analyze the prognostic values of the mRNA expression of ATP1A genes in both patients with OSC and OC patients. First, we analyzed the relationship between the mRNA expressions of distinct ATP1A gene family members and the prognoses of patients with OSC. As shown in Fig. 4, for OS and DSS, a higher mRNA expression of ATP1A3 (HR $=1.60$, CI 1.23-2.08, $p<0.001$; and $\mathrm{HR}=1.57$, CI 1.19-2.08, $p=0.002$, respectively) (Fig. 4c, d) and ATP1A4 (HR=0.75, CI 0.57-0.97, $p=0.030$; and $\mathrm{HR}=0.72$, CI 0.54-0.96, $\mathrm{p}=0.023$, respectively) (Fig. $4 \mathrm{~g}$, h) were significantly associated with shorter OS and DSS in patients with OSC. However, the mRNA expression of neither ATP1A1 (HR =1.15, CI 0.88-1.49, $p=0.298$; and $\mathrm{HR}=1.13$, CI $0.86-1.50, p=0.377$, respectively) (Fig. 4a, b) nor ATP1A2 $(\mathrm{HR}=1.26$, CI 0.97-1.63, $p=0.086$; and $\mathrm{HR}=1.30$, CI 0.98-1.73, $p=0.064$, respectively) (Fig. 4e, f) showed any correlation with OS or DSS in patients with OSC. Moreover, the results of survival analysis from the GSE26193 datasets are showed in Additional file 6: Figure S5. It was found that higher mRNA expressions of ATP1A3 $(\mathrm{HR}=1.86, \mathrm{CI} 1.13-3.07, p=0.014$; and $\mathrm{HR}=1.74$, CI $1.07-2.81, p=0.023$, respectively) and ATP1A4 $(\mathrm{HR}=1.25$, CI $1.02-1.54, p=0.029$; and $\mathrm{HR}=2.17$, CI $1.25-3.77, \mathrm{p}=0.0047$, respectively) were significantly associated with shorter OS and progressionfree survival (PFS) in patients with OC. In contrast, a higher mRNA expression of ATP1A1 was associated with longer OS or PFS (HR $=0.58$, CI $0.33-1.01, p=0.053$; and $\mathrm{HR}=0.51$, CI $0.3-0.87, p=0.011$, respectively) (Additional file 6: Figure S5). These results suggested that the mRNA expressions of ATP1A3 and ATP1A4 were closely related to the prognosis of OC. They may be used as potential biomarkers to predict the survival of patients.

Secondly, we analyzed the effects of distinct ATP1A gene family member expression on patients' prognosis in the subgroups of FIGO stage III, histological grade G3, TP53 mutation, and age $\geq 60$ years. The results showed that in patients with FIGO stage III, no significant correlation was found in ATP1A1 (HR=1.16, CI 0.87-1.56, $p=0.315)$, ATP1A2 (HR $=1.24$, CI $0.92-1.66, p=0.157)$, and ATP1A4 $(\mathrm{HR}=0.77, \mathrm{CI} 0.58-1.04, p=0.085)$, whereas the high expression of ATP1A3 $(\mathrm{HR}=1.70$, CI $1.27-2.28, p<0.001)$ was significantly associated with shorter OS (Fig. 5a-d). Higher mRNA expressions of ATP1A2 $(\mathrm{HR}=1.34, \mathrm{CI} 1.01-1.78, p=0.042)$ and 

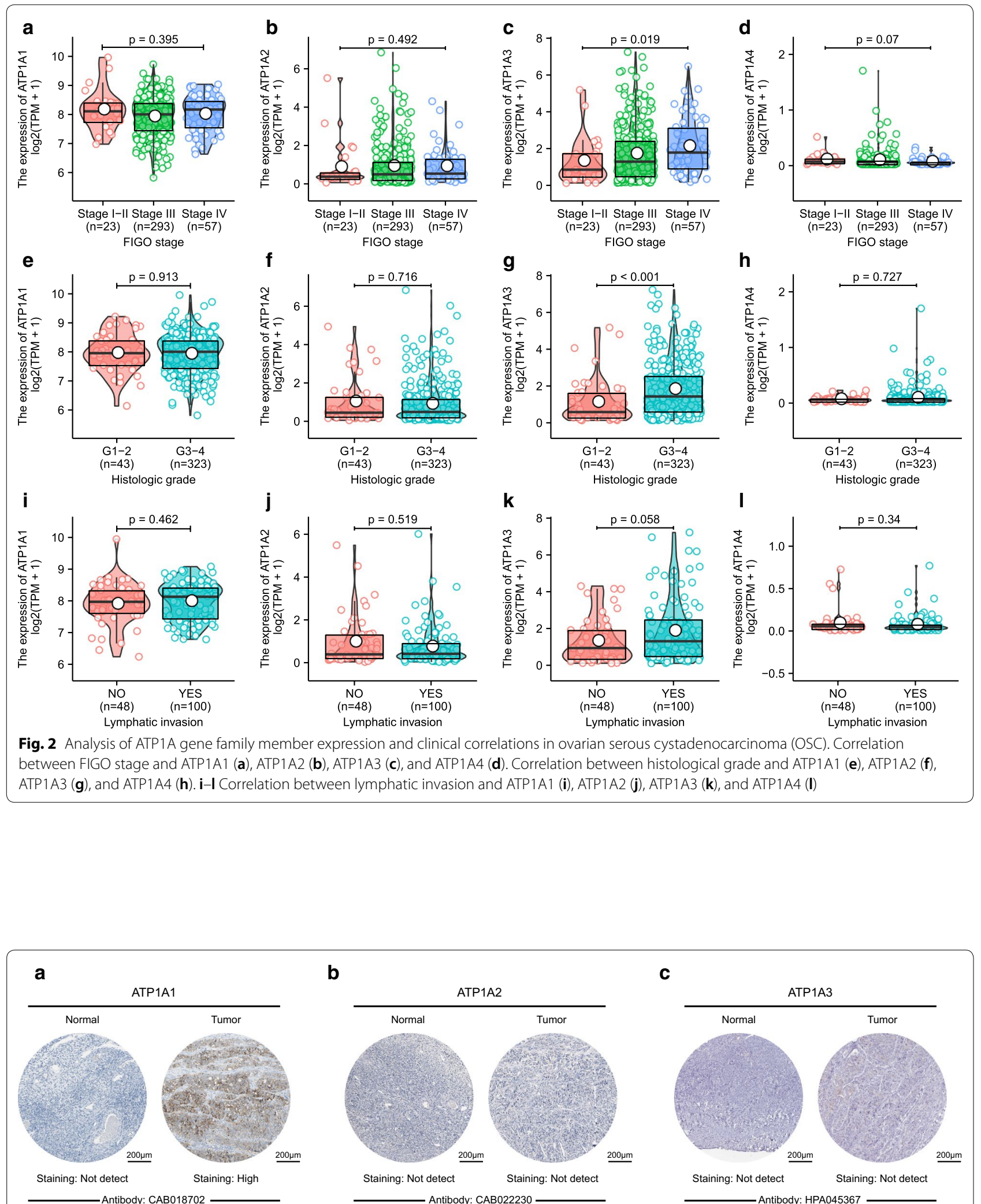

Fig. 3 Representative immunohistochemistry images of ATP1A gene family members in OSC and normal ovarian tissues (Human Protein Atlas). a ATP1A1 expression was not detected in normal ovarian tissues, whereas its high expression was detected in OSC tissues. b, c ATP1A2 and ATP1A3 expression was not detected both in normal and OSC tissues 

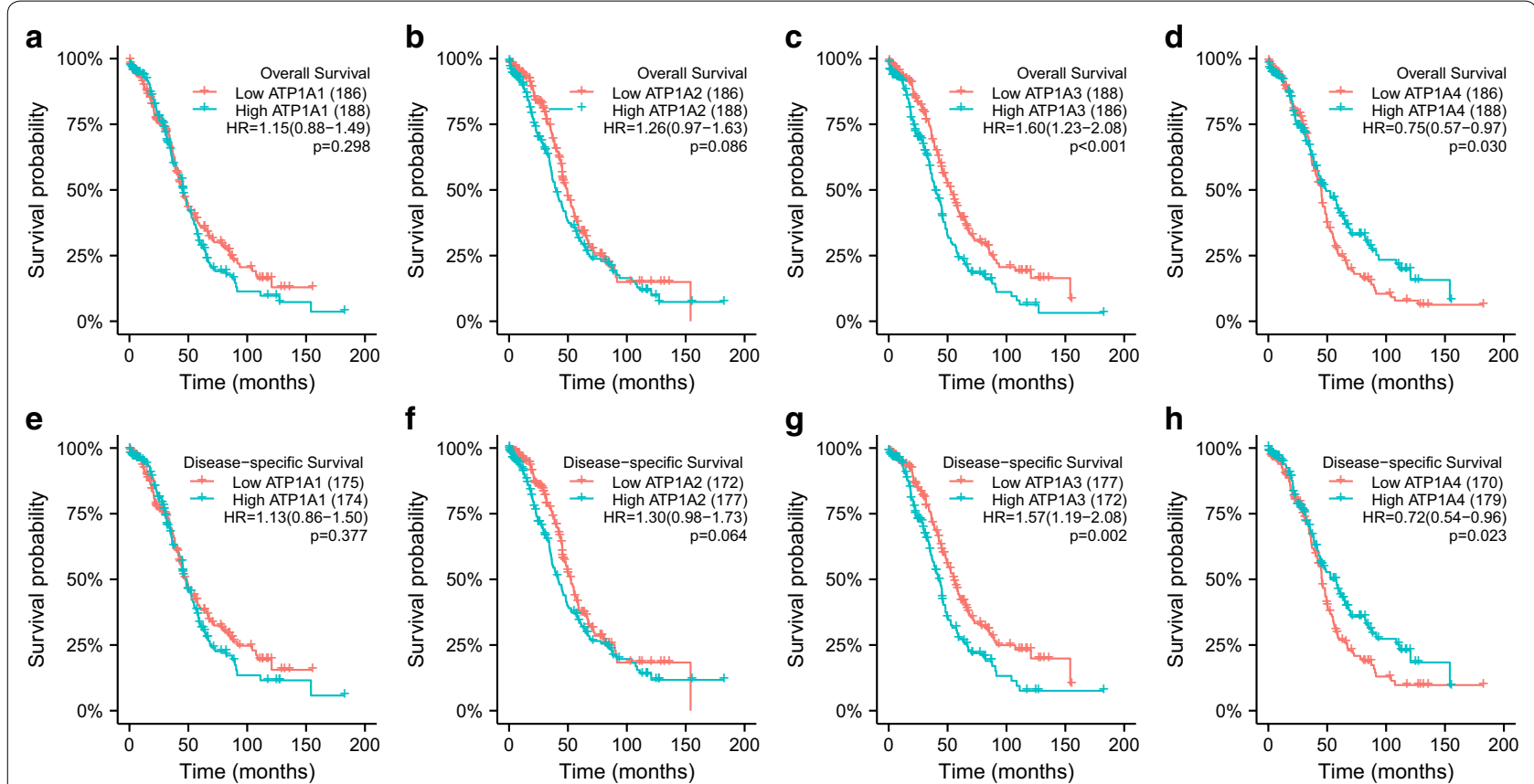

Fig. 4 Prognostic analysis of the ATP1A gene family members. $\mathbf{a}-\mathbf{d}$ Effects of ATP1A gene family members on overall survival (OS). $\mathbf{e}-\mathbf{h}$ Effects of ATP1A gene family members on disease-specific survival (DSS). ( $p<0.05$ was considered statistically significant)

ATP1A3 $(\mathrm{HR}=0.75$, CI $1.30-2.30, p<0.001)$ were significantly associated with poor OS in patients with histological grade G3, whereas no such association was noted for ATP1A1 $(\mathrm{HR}=1.20$, CI $0.91-1.59, p=0.202)$ and ATP1A4 $(\mathrm{HR}=0.79$, CI $0.60-1.06, p=0.113)$ were not (Fig. 5e-h). In addition, the high expression of ATP1A3 $(\mathrm{HR}=1.62$, CI $1.17-2.26, p=0.004)$ was significantly associated with decreased OS in patients with TP53 mutation, but no correlation was observed with ATP1A1 $(\mathrm{HR}=1.33$, CI 0.95-1.84, $p=0.094)$, ATP1A2 $(\mathrm{HR}=0.98$, CI $0.70-1.36, p=0.881)$ and ATP1A4 $(\mathrm{HR}=0.68$, CI $0.49-0.95, p=0.023$ ) (Fig. 5i-1). Furthermore, we found that the high expression of ATP1A2 $(\mathrm{HR}=1.48$, CI 1.02$2.15, p=0.039)$ and ATP1A3 $(\mathrm{HR}=2.23$, CI 1.54-3.24, $p<0.001)$ was significantly associated with poor OS in patients aged $\geq 60$ years old, whereas no such correlation was observed with ATP1A1 ( $\mathrm{HR}=1.15$, CI $0.80-1.65$, $p=0.460)$. Conversely, we found that the high expression of ATP1A4 (HR $=0.66$, CI 0.46-0.95, $p=0.027)$ was correlated with better OS (Fig. $5 \mathrm{~m}-$ p). Finally, the effects of ATP1A gene family members on DSS in patients in subgroups are shown in Additional file 7: Figure S6.

Based on the results of multivariate analysis, a genomic-clinical nomogram, including primary tumor therapy outcome, residual tumor, ATP1A2, ATP1A3, and ATP1A4, was established to predict the 1-, 3-, and 5 -year OS and DSS in patients with OC (Fig. 6a, c). The calibration curves of the nomogram for predicting these survival times indicated that it performed well (Fig. 6b, d).

To further validate our data, we tested the protein expression of the ATP1A gene family members (including ATP1A1, ATP1A2, and ATP1A3) in cancer and paracancerous tissue samples of six patients with OSC. Among these six patients, one had FIGO stage IIIA and the other five had stage IIIC. No patient had lymph node metastasis. Our results showed that ATP1A1 was positively expressed in three OSC samples and negatively expressed in all the paracancerous samples; ATP1A2 was negatively expressed in both the OSC and paracancerous samples; ATP1A3 was positively expressed in five OSC samples and three paracancerous samples. Images of ATP1A gene family member expression in tumor and paracancerous tissues are presented in Fig. 7.

\section{Mutation frequency of ATP1A gene family members}

Based on the cBioPortal database, we explored the mutation frequency of the ATP1A gene family members. The mutation rates of ATP1A1, ATP1A2, ATP1A3, and ATP1A4 were 4\%, 5\%, 3\%, and 4\%, respectively (Fig. 8).

\section{Discussion}

To date, the clinical prognosis of patients with OSC remains unsatisfactory due to the lack of predictive biomarkers for early diagnosis and effective treatment targets. Therefore, it is important to understand the 

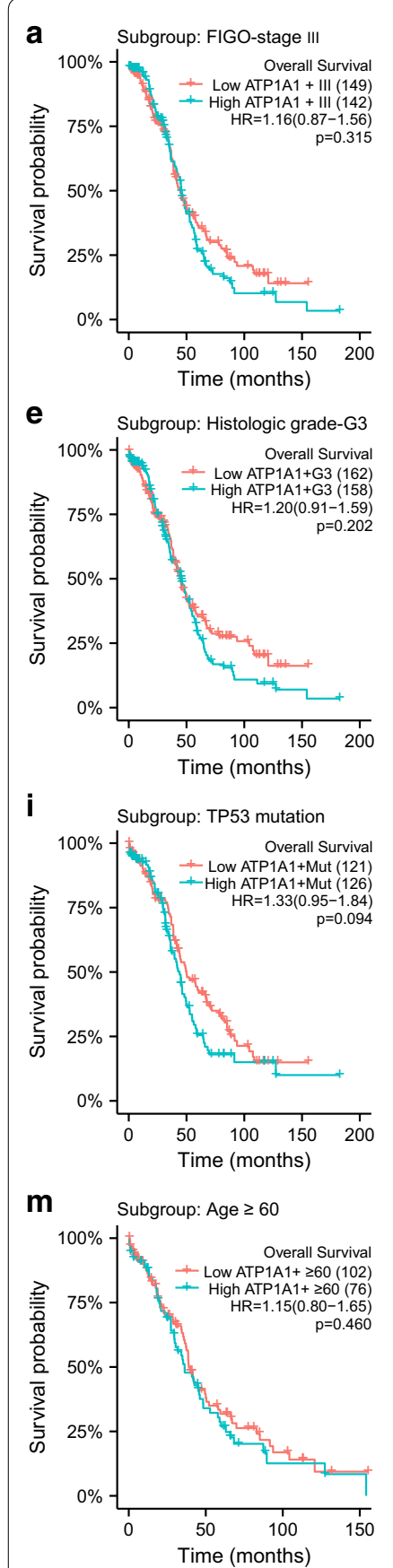
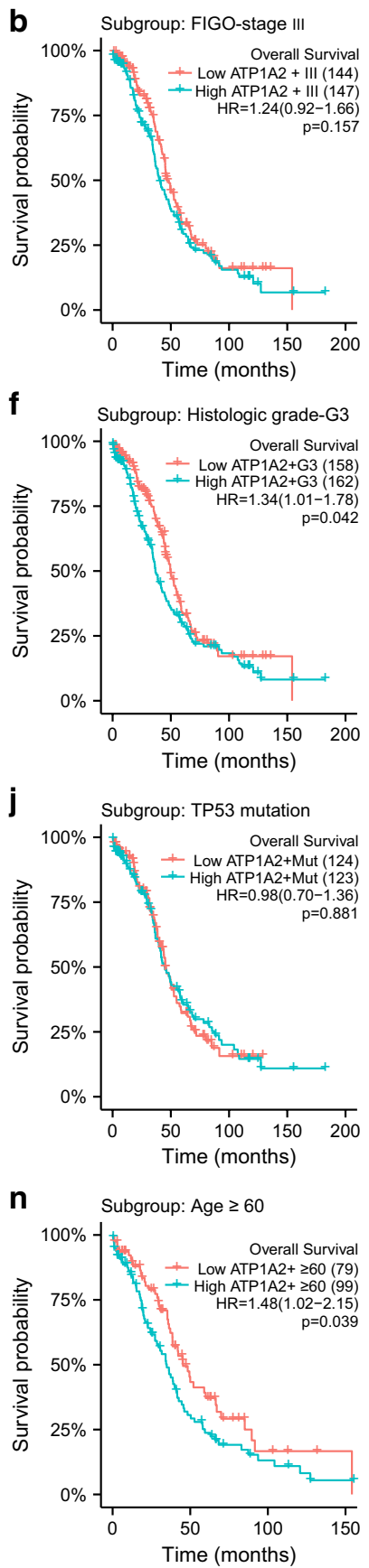
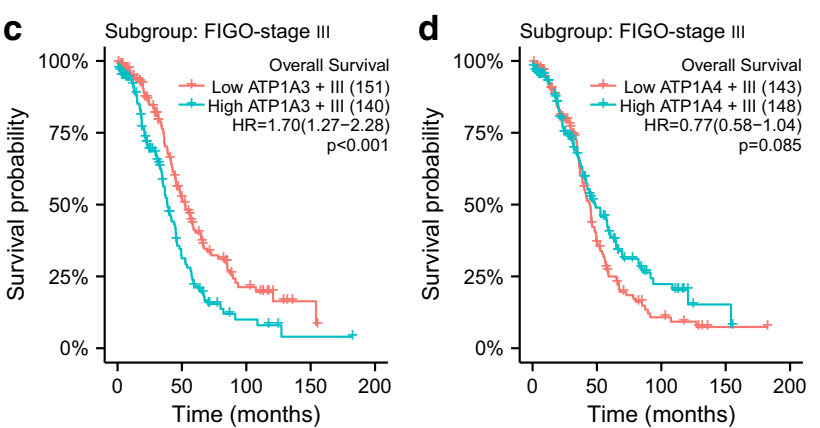

g Subgroup: Histologic grade-G3
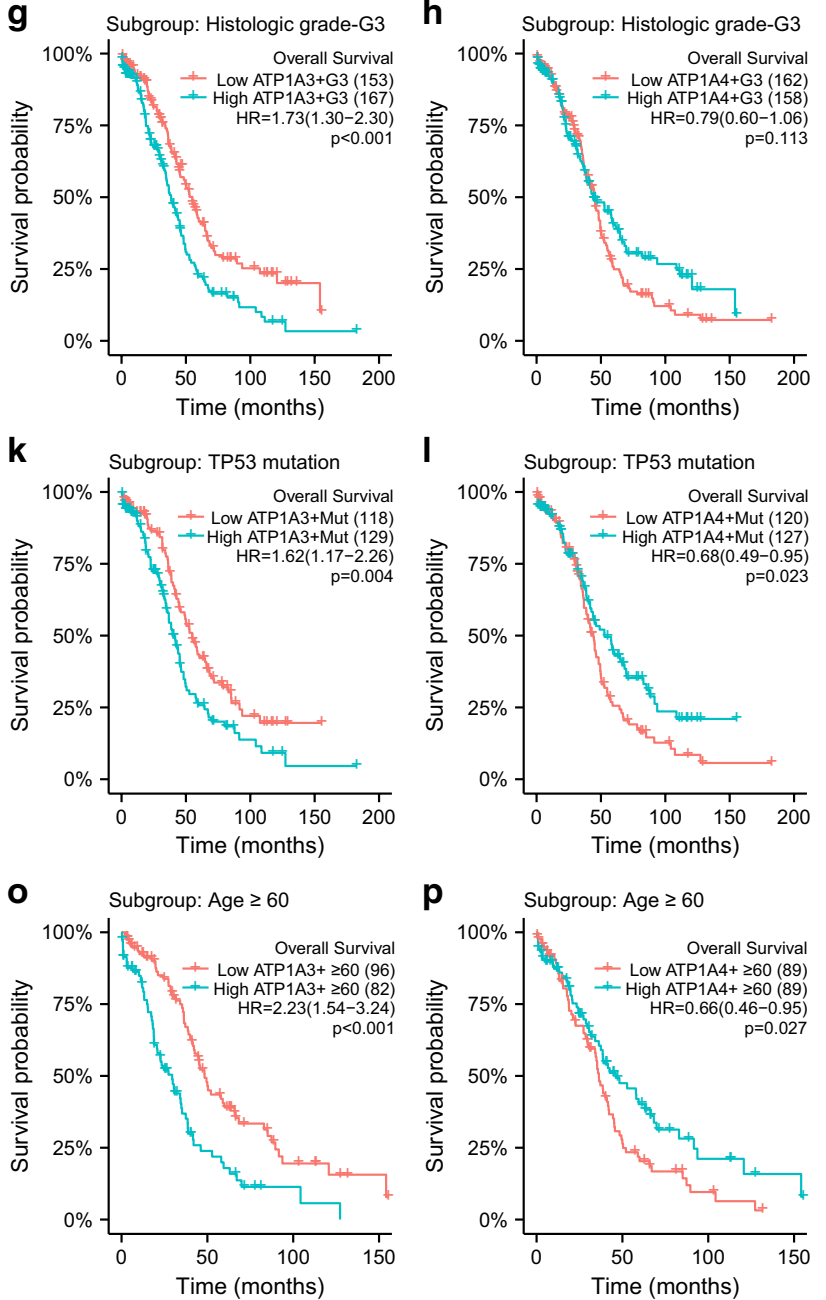

Fig. 5 Prognostic analysis of the ATP1A gene family members in subgroups for overall survival. Prognostic analysis of ATP1A1 (a), ATP1A2 (b), ATP1A3 (c), and ATP1A4 (d) for FIGO stage III. Prognostic analysis of ATP1A1 (e), ATP1A2 (f), ATP1A3 (g), and ATP1A4 (h) for histological grade G3. Prognostic analysis of ATP1A1 (i), ATP1A2 (j), ATP1A3 (k), and ATP1A4 (I) for TP53 mutation. Prognostic analysis of ATP1A1 (m), ATP1A2 (n), ATP1A3 (o), and ATP1A4 (p) for age $\geq 60$. ( $p<0.05$ was considered statistically significant)

molecular aberration underlying the occurrence and development of OSC to identify new molecular markers for early diagnosis, targeted treatment and prognosis evaluation.
In recent years, accumulated evidence has suggested the involvement of $\mathrm{Na}^{+} / \mathrm{K}^{+}$-ATPase in tumor occurrence and development. Alterations in $\mathrm{Na}^{+} / \mathrm{K}^{+}$-ATPase subunits have been observed in various tumors $[6,20]$. 


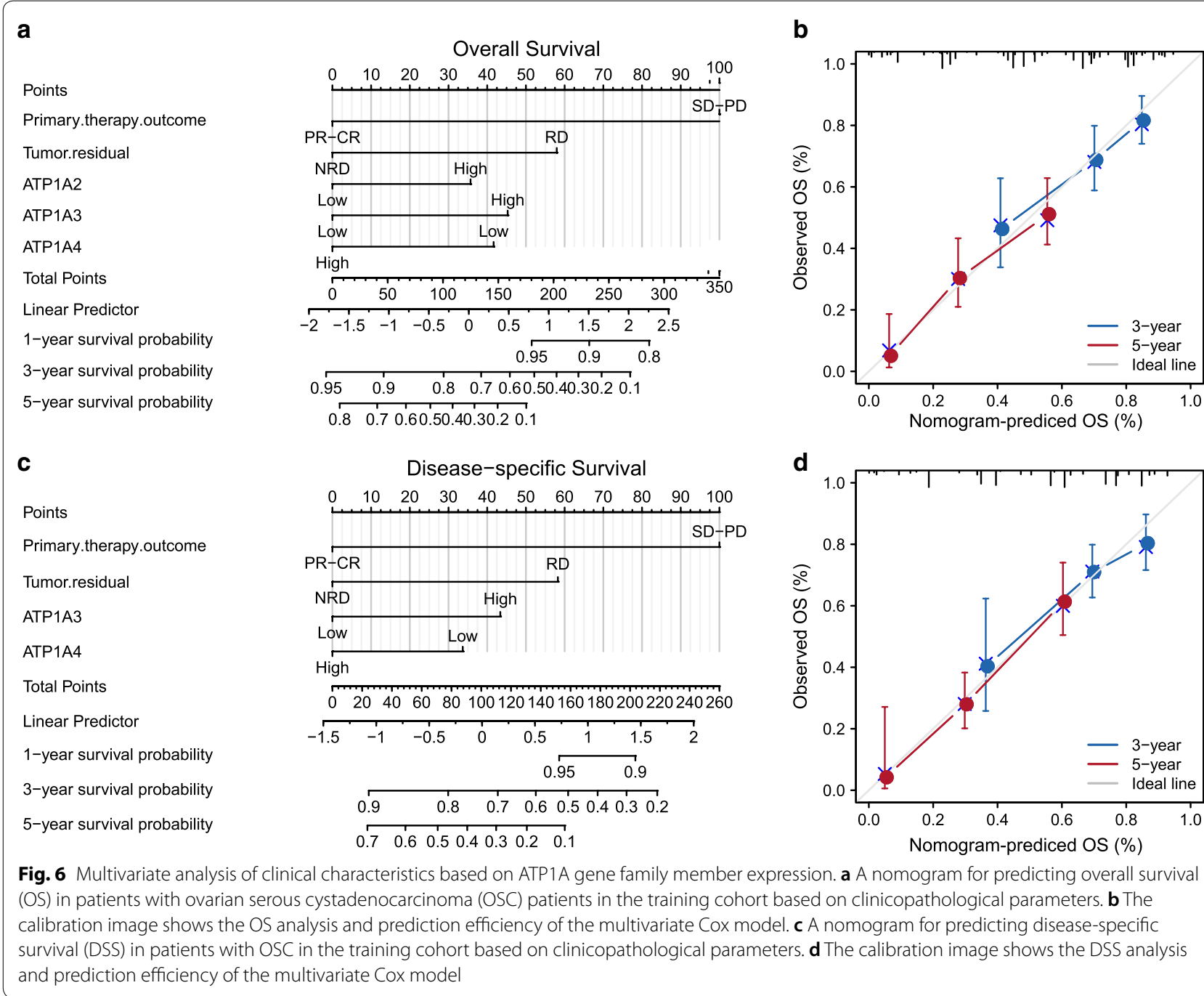

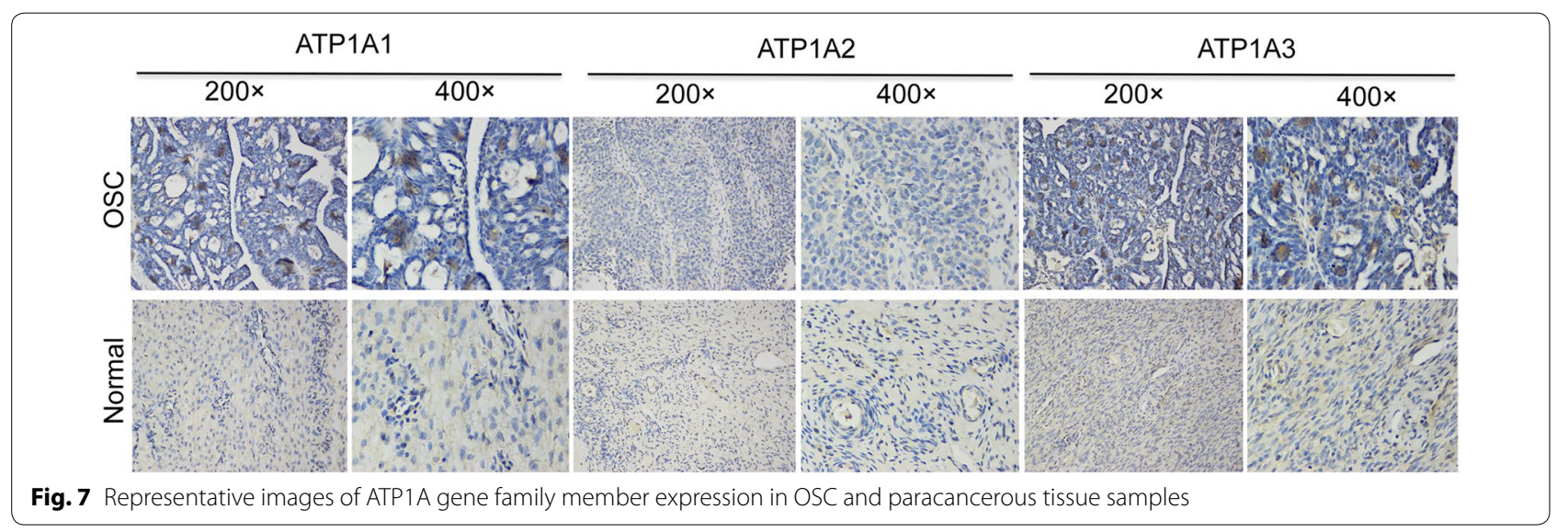




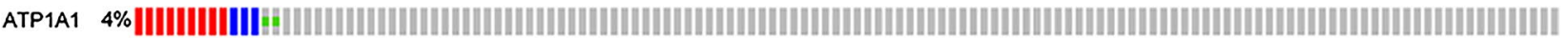 ATP1A2 $5 \%$ | AтP1A3 3\%

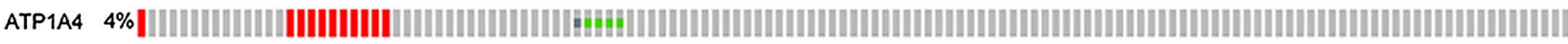 $\begin{array}{clll}\text { Genetic Alteration } & \text { Missense Mutation (unknown significance) } & \text { Amplification } & \text { No alterations } \\ & \text { \# Truncating Mutation (unknown significance) } & \text { Deep Deletion }\end{array}$}

Fig. 8 Mutation frequency of ATP1A gene family members in ovarian serous cystadenocarcinoma. The mutation frequencies of ATP1A1, ATP1A2, ATP1A3, and ATP1A4 in ovarian serous cystadenocarcinoma were 4\%,5\%,3\%, and 4\%, respectively

As an important component of $\mathrm{Na}^{+} / \mathrm{K}^{+}$-ATPase, $\alpha$ subunits play key roles in catalysis. Previous studies have found that overexpression of ATP1A1 is associated with the occurrence and development of several cancers such as breast cancer, non-small cell lung cancer, renal clear-cell carcinoma, and glioma [21-23]. However, the clinical relevance of the expression of ATP1A gene family members in OSC is still not clear.

Considering that genes have been widely used as biomarkers to predict the risk of recurrence of malignant tumors, herein, we explored the diagnostic and predictive values of the ATP1A gene family members in OSC by using a series of bioinformatics methods. We used the TCGA and GTEx databases to explore the differential mRNA expression of the four ATP1A gene family members in OSC and normal ovarian tissues. The results showed that the expression of ATP1A1 and ATP1A3 in human OSC tissues was significantly higher than that in normal ovarian tissues, and that the increase in ATP1A3 expression was significantly correlated with decreased OS and DSS. Conversely, the expression of ATP1A2 and ATP1A4 was higher in normal ovarian tissues than in tumor tissues, and the high expression of ATP1A4 in OSC tissues was significantly correlated with prolonged OS and DSS. In addition, we found that the overexpression of ATP1A2 and ATP1A3 was closely related to poor prognosis of patients with OSC with FIGO stage III, histological grade G3, TP53 mutation, and age $\geq 60$ years. However, overexpression of ATP1A4 indicates a relatively good prognosis in these subgroups. Furthermore, we identified that primary therapy outcome, residual tumor, ATP1A3 gene, and ATP1A4 gene were independent indicators of OS and DSS in OSC. Moreover, primary tumor outcome, residual tumor, ATP1A2, ATP1A3, and ATP1A4 were closely related to the risk of recurrence and mortality in OSC. Finally, we conducted preliminary detection of the ATP1A gene family proteins in the tissue samples of six patients with OSC and found that the results were consistent with our prediction. Taken together, these results suggest that abnormal expression and activation of ATP1As play a key role in the occurrence and development of OSC.

To date, the signaling pathways involved in $\mathrm{Na}^{+} / \mathrm{K}^{+}$ATPase, such as MAPK, ERK, PLC, PKC, and Ras/Raf, have been well understood in normal cells. However, only few studies have focused on these related signaling pathways in tumors [24-28]. Previous studies have reported that $\mathrm{Na}^{+} / \mathrm{K}^{+}$-ATPase can promote tumor multidrug resistance (MDR) by affecting the c-Myc, NF- $\mathrm{kB}$, and $N$-glycosylation pathways [28-30]. Furthermore, ATP1As have been gradually discovered as important therapeutic targets in malignant tumors. Cardiac glycosides are known to be specific inhibitors of $\mathrm{Na}^{+} / \mathrm{K}^{+}$ATPase enzyme [31], which inhibit enzyme activity by binding to $\alpha$ subunits [32]. Due to the anticancer effects of these drugs found in vitro in certain tumors, they are considered to be promising candidates for cancer treatment [33]. At present, cardiac glycosides or their derivatives have been evaluated in phase I and phase II clinical trials of several refractory and advanced cancers [34-37].

Finally, some limitations in our study warrant discussion. First, when comparing the differential expression of ATP1A2 and ATP1A3 in tumor and normal tissues, it was found that the results from the TCGA and ICGC databases were contradictory. Second, survival analysis based on the TCGA database indicated that a higher expression of ATP1A4 was associated with longer OS and DSS, which is contrary to the results based on the GEO database. These contradictory results might be due to the smaller number of control samples in the OV-AU dataset and the GEO database. Third, the clinical data available in these databases are limited, and data on several important factors such as tumor size, ascites, chemotherapy resistance, and CA125 level, affecting the prognosis of OSC were missing. Finally, we conducted preliminary tests on the expression of ATP1A in limited clinical samples. Although the results are consistent with the predictions, further research is still warranted. 


\section{Conclusions}

The present study demonstrated that the ATP1A gene family members are abnormally expressed in OSC tissues and are closely correlated with the clinical features and prognosis of patients with this malignancy. Thus, the expression of ATP1As may be useful biomarkers of the diagnosis and prognosis of OSC. In addition, ATP1As may become effective therapeutic targets for the treatment of OSC.

\section{Supplementary information}

Supplementary information accompanies this paper at https://doi. org/10.1186/s12935-020-01414-5.

Additional file 1: Table S1. Clinical features of OC patients from ICGC. Table S2. Clinical features of OC patients from GSE26193.

Additional file 2: Figure S1. Expression of ATP1A gene family members in ovarian cancer (OC) and its diagnostic value. (A-D) Differential expression analysis of ATP1A gene family between OC samples and normal ovarian samples based on the GEO database. (E-H) Receiver-operating characteristic (ROC) curves of ATP1A gene family members for diagnosis of $\mathrm{OC}$

Additional file 3: Figure S2. ATP1A gene family member expression in pan-cancers and paracancerous tissues. ATP1A1 (A); ATP1A2 (B); ATP1A3 (C); ATP1A4 (D) $\left({ }^{*} p<0.05,{ }^{* *} p<0.01,{ }^{* * *} p<0.001\right)$.

Additional file 4: Figure S3. Expression of ATP1A gene family members in pan-cancer cell lines. ATP1A1 (A), ATP1A2 (B), ATP1A3 (C), and ATP1A4 (D).

Additional file 5: Figure S4. Analysis of ATP1A gene family expression and clinical correlations in ovarian cancer. Correlation between FIGO stage and ATP1A1 (A), ATP1A2 (B), ATP1A3 (C), and ATP1A4 (D). Correlation between histological grade and ATP1A1 (E), ATP1A2 (F), ATP1A3 (G), and ATP1A4 (H).

Additional file 6: Figure S5. Prognostic analysis of the ATP1A gene family members in ovarian cancer. (A-D) Effects of ATP1As gene family on overall survival (OS). (E-H) Effects of ATP1A gene family members on progressionfree survival (PFS) ( $p<0.05$ was considered statistically significant).

Additional file 7: Figure S6. Prognostic analysis of ATP1A gene family members in subgroup for DSS. Prognostic analysis of ATP1A1 (A), ATP1A2 (B), ATP1A3 (C), and ATP1A4 (D) for FIGO stage III. Prognostic analysis of ATP1A1 (E), ATP1A2 (F), ATP1A3 (G), and ATP1A4 (H) for histologic grade G3. Prognostic analysis of ATP1A1 (I), ATP1A2 (J), ATP1A3 (K), and ATP1A4 (L) for TP53 mutation. Prognostic analysis of ATP1A1 (M), ATP1A2 (N), ATP1A3 (O), and ATP1A4 (P) for age $\geq 60$ ( $p<0.05$ was considered statistically significant)

\section{Abbreviations}

ATP1As: Sodium/potassium adenosine triphosphate $\left(\mathrm{Na}^{+} / \mathrm{K}^{+}\right.$-ATP)ase a-subunits; CCLE: Cancer Cell Line Encyclopedia; DSS: Disease-specific survival; FIGO: Federation of Gynecology and Obstetrics; GTEx: Genotype-Tissue Expression; HPA: The Human Protein Atlas; OS: Overall survival; OSC: Ovarian serous cystadenocarcinoma; OV-AU: Ovarian cancer-AU; PI3KJAKT: Phosphatidylinositol 3-kinase/protein kinase B; ROC: Receiver operating characteristic; TCGA: The Cancer Genome Atlas.

\section{Acknowledgements}

Not applicable.

\section{Authors' contributions}

HW and $\mathrm{HL}$ conceived the study and edited the manuscript. HW, HL, and ZYJ performed statistical analysis. XY, YSY, and LB collated and annotated the data. $L G$ revised the manuscript. All authors read and approved the final manuscript.

\section{Funding}

This research was supported by the National Natural Science Foundation of China (Grant Number 81872507).

\section{Availability of data and materials}

The datasets used and analyzed during the current study are available from the corresponding author on reasonable request.

\section{Ethics approval and consent to participate}

The gene expression profiles used in the text were downloaded from public databases, and no experiments were performed on patients and animals; thus, ethical approval was not necessary in our study.

\section{Consent of publication}

Not applicable.

\section{Competing interests}

There are no conflicts of interest to declare.

\section{Author details \\ ${ }^{1}$ Department of Gynecology Oncology, Harbin Medical University Cancer Hospital, Harbin Medical University, Harbin 150081, Heilongjiang, China. \\ ${ }^{2}$ Department of Pathology, Harbin Medical University, Harbin 150081, Heilongjiang, China. ${ }^{3}$ Department of Medical Oncology, Harbin Medi- cal University Cancer Hospital, Harbin Medical University, Harbin 150081, Heilongjiang, China. ${ }^{4}$ Department of Gynecology Oncology, Tumor Hospital of Harbin Medical University, 150 Haping Road, Harbin 150081, Heilongjiang, China. ${ }^{5}$ Department of Medical Oncology, Tumor Hospital of Harbin Medical University, Harbin 150081, Heilongjiang, China.}

Received: 17 April 2020 Accepted: 9 July 2020

Published online: 14 July 2020

\section{References}

1. Siegel RL, Miller KD, Jemal A. Cancer statistics, 2019. CA Cancer J Clin. 2019;69:7-34

2. Günakan E, Tohma YA, Tunç M, Akıllı H, Sahin H, Ayhan A. Factors associated with surgical morbidity of primary debulking in epithelial ovarian cancer. Obstet Gynecol Sci. 2020;63:64-71.

3. Matsuo K, Machida H, Yamagami W, Ebina Y, Kobayashi Y, Tabata T, et al. Intraoperative capsule rupture, postoperative chemotherapy, and survival of women with stage I epithelial ovarian cancer. Obstet Gynecol. 2019;134(5):1017-26.

4. Torre LA, Trabert B, DeSantis CE, Miller KD, Samimi G, Runowicz CD, et al. Ovarian cancer statistics, 2018. CA Cancer J Clin. 2018;68:284-96.

5. Blanco G. Na, K-ATPase subunit heterogeneity as a mechanism for tissuespecific ion regulation. Semin Nephrol. 2008;25:292-303.

6. Mijatovic T, Roland I, Van Quaquebeke E, Nilsson B, Mathieu A, Van Vynckt F, et al. The alpha1 subunit of the sodium pump could represent a novel target to combat non-small cell lung cancers. J Pathol. 2007;212(2):170-9.

7. Suñol M, Cusi V, Cruz O, Kiss R, Lefranc F. Immunohistochemical analyses of alpha1 and alpha3 $\mathrm{Na}+/ \mathrm{K}+-$-ATPase subunit expression in medulloblastomas. Anticancer Res. 2011;31:953-8.

8. Li L, Feng R, Xu Q, Zhang F, Liu T, Cao J, et al. Expression of the $\beta 3$ subunit of $\mathrm{Na}+/ \mathrm{K}+$-ATPase is increased in gastric cancer and regulates gastric cancer cell progression and prognosis via the PI3/AKT pathway. Oncotarget. 2017;8:84285-99.

9. Li S, Dai Z, Yang D, Li W, Dai H, Sun B, et al. Targeting $\beta 2$ subunit of Na+/ $\mathrm{K}+-$-ATPase induces glioblastoma cell apoptosis through elevation of intracellular Ca2. Am J Cancer Res. 2019;9:1293-308.

10. Espineda C, Seligson DB, James Ball W, Rao J, Palotie A, Horvath S, et al. Analysis of the Na, K-ATPase alpha- and beta-subunit expression profiles of bladder cancer using tissue microarrays. Cancer. 2003:97:1859-68.

11. Tomczak K, Czerwińska P, Wiznerowicz M. The Cancer Genome Atlas (TCGA): an immeasurable source of knowledge. Contemp Oncol. 2015;19:A68-77.

12. Lonsdale J, Thomas J, Salvatore M, Phillips R, Lo E, Shad S. The genotypetissue expression (GTEx) project. Nat Genet. 2013;45:580-5. 
13. Mary G, Brian C, Mim H, Kristupas R, Fran M, Akhil K, et al. The UCSC Xena platform for public and private cancer genomics data visualization and interpretation. bioRxiv. 2019. https://doi.org/10.1101/326470.

14. Davis S, Meltzer PS. GEOquery: a bridge between the gene expression omnibus (GEO) and BioConductor. Bioinformatics. 2007;23:1846-7.

15. Mateescu B, Batista L, Cardon M, Gruosso T, De Feraudy Y, Mariani O, et al. miR-141 and miR-200a act on ovarian tumorigenesis by controlling oxidative stress response. Nat Med. 2011;17:1627-35.

16. Ritchie ME, Phipson B, Wu DI, Hu Y, Law CW, Shi W, et al. Limma powers differential expression analyses for RNA-sequencing and microarray studies. Nucleic Acids Res. 2015;43:e47.

17. Asplund A, Edqvist PH, Schwenk JM, Pontén F. Antibodies for profiling the human proteome-The Human Protein Atlas as a resource for cancer research. Proteomics. 2012;12(13):2067-77.

18. Barretina J, Caponigro G, Stransky N, Venkatesan K, Margolin AA, Kim S, et al. The Cancer Cell Line Encyclopedia enables predictive modelling of anticancer drug sensitivity. Nature. 2012;483:603-7.

19. Gao J, Aksoy BA, Dogrusoz U, Dresdner G, Gross B, Sumer SO, et al. Integrative analysis of complex cancer genomics and clinical profiles using the cBioPortal. Sci Signal. 2013;6:pl1.

20. Rajasekaran SA, Huynh TP, Wolle DG, Espineda CE, Inge LJ, Skay A, et al. $\mathrm{Na}$, K-ATPase subunits as markers for epithelial-mesenchymal transition in cancer and fibrosis. Mol Cancer Ther. 2012;9:1515-24.

21. Lefranc F, Mijatovic T, Kondo Y, Sauvage S, Roland I, Debeir O, et al. Targeting the alpha 1 subunit of the sodium pump to combat glioblastoma cells. Neurosurgery. 2008;62(1):211-21.

22. Seligson DB, Rajasekaran SA, Yu H, Liu X, Eeva M, et al. Na, K-adenosine triphosphatase alpha1-subunit predicts survival of renal clear cell carcinoma. J Urol. 2008;179:338-45.

23. Winnicka K, Bielawski K, Bielawska A, Surazyński A. Antiproliferative activity of derivatives of ouabain, digoxin and proscillaridin A in human MCF-7 and MDA-MB-231 breast cancer cells. Biol Pharm Bull. 2008;31:1131-40.

24. Mijatovic T, Van Quaquebeke E, Delest B, Debeir O, Darro F, Kiss R. Cardiotonic steroids on the road to anti-cancer therapy. Biochim Biophys Acta. 2007; 1776:32-57

25. Mijatovic T, Ingrassia L, Facchini V, Kiss R. Na ${ }^{+} / K^{+}$-ATPase alpha subunits as new targets in anticancer therapy. Expert Opin Ther Targets. 2008;12:1403-17.

26. Newman RA, Yang P, Pawlus AD, Block Kl. Cardiac glycosides as novel cancer therapeutic agents. Mol Interv. 2008:8:36-49.

27. Cerella C, Dicato M, Diederich M. Assembling the puzzle of anticancer mechanisms triggered by cardiac glycosides. Mitochondrion. 2013;13:225-34
28. Mijatovic T, Op De Beek A, Van Quaquebeke E, Dewelle J, Darro F, de Launoit Y, et al. The cardenolide UNBS1450 is able to deactivate NF-kBmediated cytoprotective effects in human non-small-cell-lung cancer (NSCLC) cells. Mol Cancer Ther. 2006;5:391-9.

29. Chen Y, Bathula SR, Li J, Huang L. Multifunctional nanoparticles delivering small interfering RNA and doxorubicin overcome drug resistance in cancer. J Biol Chem. 2010;285:22639-50.

30. Beheshti Zavareh R, Lau KS, Hurren R, Datti A, Ashline DJ, Gronda M, et al. Inhibition of the sodium/potassium ATPase impairs N-glycan expression and function. Cancer Res. 2008;68:6688-97.

31. Schatzmann HJ. Cardiac glycosides as inhibitors of active potassium and sodium transport by erythrocyte membrane. Helv Physiol Pharmacol Acta. 1953;11:346

32. Woo AL, James PF, Lingrel JB. Characterization of the fourth alpha isoform of the Na, K-ATPase. J Membr Biol. 1999;169:39-44.

33. Reddy D, Kumavath R, Ghosh P, Barh D. Lanatoside C induces G2/M cell cycle arrest and suppresses cancer cell growth by attenuating MAPK, Wnt, JAK-STAT, and PI3K/AKT/mTOR signaling pathways. Biomolecules. 2019;9:792

34. Platz EA, Yegnasubramanian S, Liu JO, Chong CR, Shim JS, Kenfield SA, et al. A novel two-stage, transdisciplinary study identifies digoxin as a possible drug for prostate cancer treatment. Cancer Discov. 2011;1:68-77.

35. Meng Z, Garrett CR, Shen Y, Liu L, Yang P, Huo Y, et al. Prospective randomised evaluation of traditional Chinese medicine combined with chemotherapy: a randomised phase II study of wild toad extract plus gemcitabine in patients with advanced pancreatic adenocarcinomas. $\mathrm{Br} \mathrm{J}$ Cancer. 2012;107:411-6.

36. Mekhail T, Kaur H, Ganapathi R, Budd GT, Elson P, Bukowski RM, et al. Phase 1 trial of Anvirzel in patients with refractory solid tumors. Invest New Drugs. 2006;24:423-7.

37. Hong DS, Henary H, Falchook GS, Naing A, Fu S, Moulder S, et al. First-inhuman study of pbi-05204, an oleander-derived inhibitor of akt, fgf-2, nf-kB and p70s6k, in patients with advanced solid tumors. Invest New Drugs. 2014;32:1204-12.

\section{Publisher's Note}

Springer Nature remains neutral with regard to jurisdictional claims in published maps and institutional affiliations.
Ready to submit your research? Choose BMC and benefit from:

- fast, convenient online submission

- thorough peer review by experienced researchers in your field

- rapid publication on acceptance

- support for research data, including large and complex data types

- gold Open Access which fosters wider collaboration and increased citations

- maximum visibility for your research: over $100 \mathrm{M}$ website views per year

At BMC, research is always in progress.

Learn more biomedcentral.com/submissions 